Article

\title{
Impact of Competitive Capabilities on Sustainable Manufacturing Applications in Romanian SMEs from the Textile Industry
}

\author{
Eduard Gabriel Ceptureanu 1,*(D), Sebastian Ion Ceptureanu ${ }^{1}$ (B), Razvan Bologa ${ }^{2}$ \\ and Ramona Bologa ${ }^{2}$ \\ 1 Department of Management, The Bucharest University of Economic Studies, Bucharest 010374, Romania; \\ sebastian.ceptureanu@man.ase.ro \\ 2 Department of Computer Science and Cybernetics, The Bucharest University of Economic Studies, \\ Bucharest 010374, Romania; razvanbologa@ase.ro (R.B.); ramona.bologa@ie.ase.ro (R.B.) \\ * Correspondence: eduard.ceptureanu@man.ase.ro; Tel.: +40-074-221-4578
}

Received: 25 February 2018; Accepted: 19 March 2018; Published: 23 March 2018 updates

\begin{abstract}
This paper examines the impact of competitive capabilities on sustainable manufacturing practices in Romanian small and medium-sized enterprises from the textile industry. We developed an econometric model based on previous research conducted by prestigious specialists and validated on a survey data from 221 Romanian small and medium enterprises from the textile industry. Our article proposes a number of implications to encourage entrepreneurs and managers from textile industry to engage in pro-environmental behaviour.
\end{abstract}

Keywords: sustainable manufacturing; competitive capabilities; environmental framework; textile industry

\section{Introduction}

Sustainable manufacturing (SM) is a relatively new field that has received attention during the last two decades. It has evolved rapidly from traditional operational practices to using innovative processes that consider social, environmental and economic effects [1]. Specifically, SM ensures that operational processes such as product design, procurement, managerial practices, quality control, selecting appropriate technology, scheduling, maintenance, production, and packaging have no negative effects on natural resources and stakeholders throughout the product's lifetime [2]. SM has become an important topic that can positively contribute to global GDP and sustainability awareness, particularly when we recognise that the manufacturing of goods contributes over 20 percent of carbon dioxide emissions worldwide [3].

Although there is no universally accepted definition for the term "sustainable manufacturing," numerous efforts have been made in the recent past, with many more concurrent efforts well underway. The U.S. Department of Commerce defines sustainable manufacturing as: "the creation of manufactured products that use processes that minimize negative environmental impacts, conserve energy and natural resources, are safe for employees, communities, and consumers and are economically sound" [4].

Further, according to The National Council for Advanced Manufacturing (NACFAM) in the U.S. [5] sustainable manufacturing includes the manufacturing of "sustainable" products and the sustainable manufacturing of all products. The former includes manufacturing of renewable energy, energy efficiency, green building, and other "green" \& social equity-related products, and the latter emphasizes the sustainable manufacturing of all products taking into account the full sustainability/total life-cycle issues related to the products manufactured. 
Research on SM has historically focused on Environmentally Conscious Manufacturing (ECM) [6], the formation of the 'Rs' strategies (e.g., reduction, remanufacturing, recycling and reuse, etc.) [7], and identifying good practices of SM [8]. The environmental, economic and social effects of growing $\mathrm{CO}_{2}$ emissions, waste in water, energy and natural resources, toxic materials and products, and so on, have enforced a new manufacturing philosophy that respects the direct and indirect impact of manufacturing activities on our planet as well as valuing the positive operational effects on cost, quality, adaptability and responsiveness of products and services.

The main themes of SM research tend to develop environmental indicators or to assess the environmental impact of SM $[9,10]$. Seuring and Müller [11] argued that sustainability is often abridged to environmental improvements, which call for an integrated perspective that combines sustainability issues. Moreover, an absence of relevant theoretical frameworks that lay the foundation for such SM practices, factors and output is evident. Diverse research contexts including both large plants and SMEs are also observed. Researchers articulated a need for further SM research within the context of SMEs that link SME's adoption of sustainable manufacturing practices (SMP) to performance benefits [12].

Despite recent SM research, there have been limited studies in SMEs concerning practices and impact on their competitive capabilities when using SM. Realising the above-mentioned gap, the key objective of this study is to investigate the impact of technology, organisational and environmental practice on SMP, as well as reviewing the effects of these practices on the competitive capabilities of a wide range of Romanian SMEs by using the partial least squares approach to structural equation modelling (PLS-SEM) model.

The current understanding of SMP assumes that SMEs are a particularly pertinent context to study for many reasons. First, global industrialisation has given SMEs tremendous opportunities to adopt regulations concerning their environmental responsibilities and manufacturing standards that lead to less waste [13]. Second, sustainable development pressures such as increasing energy prices and pollution rates urge SMEs to adopt manufacturing paradigms that allow them to compete globally. This is particularly relevant as SMEs are responsible for about $64 \%$ of industrial environmental impact [14]. Third, there is a great deal of ambiguity concerning SMEs' knowledge of the best ways for sustainable improvement which is accompanied with a shortage of capital, personnel and other resources [15]. Fourth, prior research on the key factors and operational outcomes of SM in SMEs in Romania barely exists. According to Ramayah et al. [16], it is vital to validate the link between implementing SMP and the corresponding performance benefits. Thus, we may assert that this study contributes to theory and practice of SM as well as SMEs research.

The research results will endow information for competitive capabilities on sustainable management applications from the Romanian textile industry. Insights developed from extant literature, research hypotheses and theoretical models have been organized in Section 2. Section 3 presents the research methodology for obtaining data and explanatory variables data analysis and results, followed in Section 4 by discussion and findings and Conclusions covered in Section 5.

Regarding the novelty of the paper, we must emphasize that, as far as we know, is the first paper ever to treat the linkage between competitive capabilities and sustainable manufacturing application in Romanian SMEs from the textile industry. Accordingly, this study presents detailed insights from one of the most important Romanian industry in terms of exports.

\section{Research Hypotheses and Theoretical Model}

\subsection{Technology-Organization-Environment Framework Applications for SMP}

The TOE framework has been developed by DePietro et al. [17] to reflect three contexts through which a firm implements innovative practices. In this study we modify the TOE framework in order to emphasize the competitive capabilities. Therefore, the technological context reflects technical infrastructure, processes and capabilities that influence the implementation of innovative instruments 
and practices, while the organizational context involves resources and interactions concerned with the new innovation. The environmental context reflects external aspects such as competition, stakeholder pressures and the regulatory environment that influence the new innovation.

However, studies that have used the TOE framework in sustainability research are scarce. Current examples involve the green supply chain [18] and green IT initiatives [19]. Hence, identifying the key determinants of SMP using the TOE framework is an apt choice due to its generic nature and applicability across a wide variety of contexts. The framework is also appropriate as the theoretical foundation for diagnosing sustainable initiatives and practices [20,21].

Advanced technology has a vital impact on sustainable initiatives from different perspectives. Routroy and Kumar [22] contended that technology applications are key antecedents for implementing green practices in manufacturing organizations. Technology infrastructure can also make manufacturing operations such as material movement in the production line, power transmission, water management and waste control more sustainable through reducing the consumption of energy and cost of operations as well as increasing the throughput ratio. Chuang and Yang [23] indicated that green design, green manufacturing processes, and green packaging are a result of advanced applications and innovation. With regard to technology competence, Ifinedo [24] assumed that when technology competence concerning specific innovative practices is high, firms are more inclined to effectively implement these practices. This can also be applied to SMP when technical knowledge and expertise related to sustainable technologies are high. For example, promoting technical knowledge and skills concerning pollution, waste prevention, and the value of green technology are essential factors of firm's sustainable practices [25]. Technical knowledge competence also contributes in enhancing the performance of green product innovations in manufacturing firms [26].

As a result, the following hypotheses are established:

H1. Technology infrastructure positively impact SMP.

H2. Technology competence positively impact SMP.

The environmental context includes the size and structure of the industry, the firm's competitors, the macroeconomic context, and the regulatory environment [17]. Also, we modify the TOE framework in order to emphasize firms' sustainable practices and behaviors.

Environmental regulations have emerged as key factors of sustainable practices in many contexts. Regulations guide sustainability policies and processes in organisations and offer guidelines that shape sustainable behaviours and actions. Romania's environmental regulations have been gradually underpinned by laws, executive orders and ministerial decrees for the protection and development of many aspects of the local environment. Government regulations impose direct pressure over organisations and reflect local and international concerns regarding clean production, resource utilisation and social responsibilities. In this regard, it is not surprising that sustainability research initially recognised the significant influence of governmental regulations on sustainable manufacturing. Roni et al. [27] considered that the legislation and incentives imposed by the local government have forced Malaysian manufacturers to consider SMP of high priority. Using the analytical hierarchy process (AHP), Shankar et al. [28] and Mittal and Sangwan [29] analysed common factors of green manufacturing in Indian and Malaysian organisations. They indicated that current and imminent legislation are one of the top factors that lead to efficient resource utilization and clean production in manufacturing organisations. This notion is also supported by Govindan et al. [30] who drew on a fuzzy multi-criteria approach to revisit the link between compliance with regulations and maintaining green manufacturing processes. With regard to the sustainable supply chain, Zhu and Geng [31] contemplated regulations as coercive pressures that have the potential to force the implementation of supply chain practices in Chinese factories. Researchers have also highlighted the contribution of environmental pressures that are brought about by the power of customers, media, competitors, suppliers, investors, and non-governmental organizations, etc., that affect an organisation's decisions to implement sustainability initiatives. Schrettle et al. [32] considered environmental pressures as 
exogenous factors that influence organisations' sustainability practices beside local and international environmental regulations. Mittal and Sangwan [29] revealed that environmental pressures are ranked second by experts in terms of their influence on sustainable manufacturing. Customers' environmental concerns, for example, drive firms to make their products and services green sensitive since customers usually prefer products that are environmentally friendly [27]. Similarly, pressure from non-governmental and voluntary organisations supported by public media can play a crucial part in influencing sustainable practices in organisations [33]. These pressures can also be extended to drive strategic green initiatives in organisations. Accordingly, the following hypotheses can be delineated:

H3. Environmental pressures positively impact SMP.

H4. Environmental regulations positively impact SMP.

Although we have offered insights into the role of the technological and environmental factors in influencing SMP, organisational determinants highlighted by top management support and employees' involvement in sustainability initiatives provide the bond that ensures the effectiveness of SMP. Using survey data and case studies from wine producing SMEs in South Africa, Hamann et al. [34] demonstrated that managers' environmental responsibility is a vital determinant for wineries' environmental practices. Vinodh et al. [35] identified the mutual relationship as among the most influential factors that drive the implementation of a lean sustainable manufacturing system. Their study revealed that top management commitment is the main force that pushes SMP in Indian automotive companies. Bhardwaj [25] used resource-based theory and value chain analysis to develop a sustainability strategy model in Indian organisations. His findings suggested that management support is a key success for executing sustainable strategies in Indian organisations. In summary, top managers can stimulate their employees, spread a positive attitude and provide financial support for employing sustainable initiatives [12]. In the same vein, employees' involvement in rethinking traditional manufacturing operations and their impact on the environment could enhance sustainable practices by establishing a culture of shared responsibility, control and goal internalisation concerning sustainability [36]. Employees' involvement can also drive sustainable manufacturing when they affect decisions and champion sustainable efforts at various organisational levels. Thus, the former argument may lead to the following hypotheses:

H5. Management support positively impact SMP.

H6. Employees' involvement positively impact SMP.

\subsection{Competitive Capabilities and SMP}

Competitive capabilities reflect the power of generating superior value for consumers that outperform competitors. It usually covers dimensions of competitiveness such as quality, cost, efficiency, responsiveness, adaptability, innovation, productivity, and so on. For the purpose of our study, we focus only on quality, cost, responsiveness and adaptability as the most acceptable measures of competitive capabilities in operations research [37]. A firm can enjoy these capabilities by affording a product or service that meets customer's expectations, is offered at a low cost, responds to circumstances and customers' desires and is delivered fast. In their seminal article, Porter and van der Linde [38] argued that green practices are highly associated with competitiveness. Green practices can lead to vast savings in all types of resources, less downtime, better utilisation of by-products, safer workplace conditions, reductions in operations and product handling costs, higher product quality, and higher product resale and scrap value [38]. As a result, these enhancements in products and processes can also increase the adaptability of manufacturing operations and speed up product and responsiveness to customers [25]. Hence, sustainable manufacturing can yield valuable products with a high sustainable impact through the efficient use of resources [29]. In total, SMP can minimise the cost of production and add value to the final product with less environmental and social impact [39]. Besides, SMP can improve production processes leading to quality products that satisfy customers' 
expectations and help grow an enterprise's market share [40]. Ramayah et al. [16] examined the impact of SMP in Malaysian SMEs and indicated that practices such as reducing solid waste have a positive effect on competitive performance. In their study of companies from varied sectors in Turkey, Sezen and Çankaya [41] inferred that green manufacturing applications positively impact operations performance through enhancing production efficiency and occupational safety, and minimising production cost. The effects of SMP are incremental and can boost competitive advantages and profit in the long term [12]. Based on the above discussion, we can hypothesise that SMP has a positive impact on competitive capabilities as follows:

H7. SMP have a positive impact on textile product cost.

H8. SMP have a positive impact on textile product quality.

H9. SMP have a positive impact on responsiveness to the market of textile products.

H10. SMP have a positive impact on textile production adaptability to the market.

Figure 1 illustrates the proposed research model and hypotheses based on the former discussion.

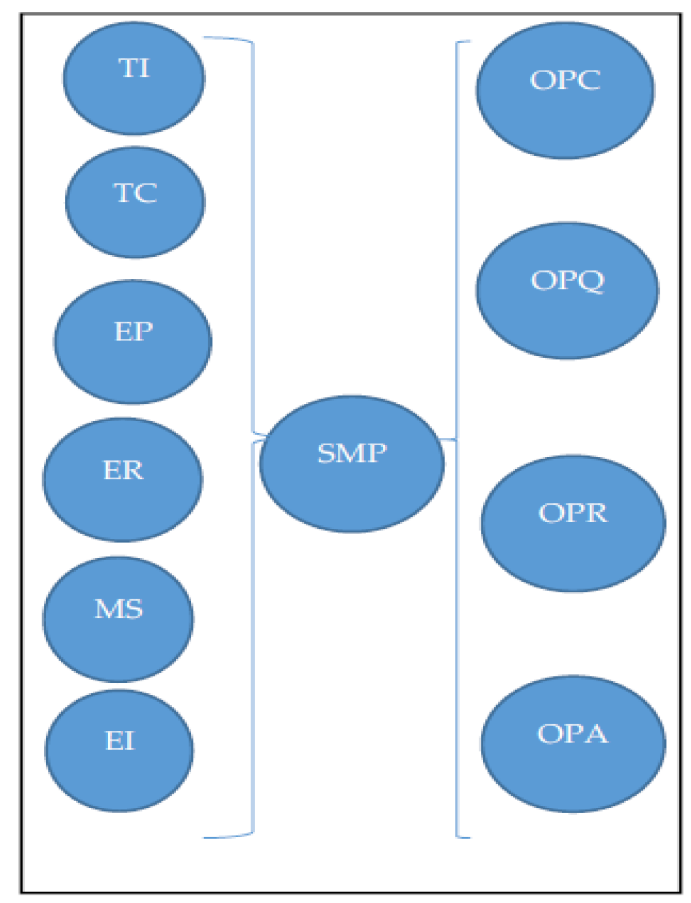

Figure 1. Research model. Note: TI-technology infrastructure; TC—technology competence; $\mathrm{EP}$-environmental pressures; ER-environmental regulations; SMP—sustainable manufacturing practices; MS—management support; EI—employees' involvement; OPC—cost; OPQ—quality; OPR—responsiveness, OPA—adaptability.

\section{Research Methodology}

The research methodology is conducted in three phases. The cross-sectional survey instrument was firstly designed and validated based on prior research. Then, the instrument was sent to a stratified random sample of managers in a wide spectrum of SMEs. Finally, the responses were validated by relevant statistical tests to ensure their adequacy for further analysis.

\subsection{Instrument Development and Validity}

The survey entails multiple reflective items that are measured using the Likert scale, ranging from 1 "strongly disagree" to 5 "strongly agree". Operationalisation of these items is derived from 
previous literature which lends high validity to the results (see Table 1). Items representing SMP are adapted from Despeisse et al. [8] and Rusinko [42]. The items reflect the use of energy, water and materials as well as reducing emissions and the waste of water and solids. Competitive capabilities are assessed by 14 items that reflect the cost (OPC), quality (OPQ), responsiveness (OPR) and adaptability (OPA) dimensions. The items are adapted from Conceptia Software Technologies [43]. Environmental regulations (ER) are presented as two items that reflect the level of national and regional regulations regarding waste, emissions, cleaner production, and so on, while the environmental pressures (EP) items include pressures from customers, media and competitors. Items of both variables are adapted from Zhu and Geng [31]. Technology infrastructure (TI) is assessed by three items adapted from Robert and Varun [44] to manifest using information, communication, networking, smart devices and manufacturing technology. Items measuring technology competence (TC) are adapted from Shankar et al. [28]. The items represent technology skills, training and resources. Management support (MS) is evaluated using two items concerning top managers' commitment to reduce waste, save energy and take necessary decisions to foster sustainability. The items are adapted from [12] and Roni et al. [27]. Employees' control over their work and responsibility for protecting the environment are used to delineate the employees' involvement (EI) variable. The items are adapted from Yusoff et al. [36]. The second part of the questionnaire is designed to collect demographic information. Content validity is further assessed following the guidelines of Cooper and Schindler [45].

Table 1. Research constructs.

\begin{tabular}{lc}
\hline & Competitive Capabilities \\
\hline CCC1 & Overhead cost is low \\
CCC2 & Low prices \\
CCC3 & Low costs of raw materials \\
CCQ1 & High quality of textile products \\
CCQ2 & Low rate of defects on textile products \\
CCQ3 & Appropriate specifications of textile products \\
CCQ4 & Appropriate working conditions and safety in the company \\
CCQ5 & Textile products do not harm the environment \\
CCR1 & Rapid response to our customer needs and behaviour \\
CCR2 & R\&D responsiveness to the market \\
CCF1 & Amount of products are quickly altered \\
CCF2 & Rapid introduction of products on the market \\
CCF3 & A broad range of textile products \\
CCF4 & We customize textile products to customer needs \\
\hline & Sustainable Manufacturing Practices \\
\hline SMP1 & Reducing energy use \\
SMP2 & Improving water use \\
SMP3 & Reducing material use \\
SMP4 & Reducing emissions \\
SMP5 & Reducing waste water \\
SMP6 & Reducing solid waste \\
\hline & Extent of environmental pressures from customers \\
\hline ER1 & Extent of environmental pressures from suppliers \\
ER2 & Extent of environmental pressures from competitors \\
\hline & Level of national environmental regulations \\
\hline EP1 & EPel of local environmental regulations \\
EP3 & Environmental Pressures \\
\hline
\end{tabular}


Table 1. Cont.

\begin{tabular}{cc}
\hline & Competitive Capabilities \\
\hline TI1 & Technology Infrastructure \\
T12 & Our firm uses information, communication and networking technology \\
TI3 & Our firm uses new innovations on manufacturing \\
\hline TC1 & Technology Competence \\
TC2 & Our employees have the skills to manage new technology and smart devices \\
TC3 & Our employees are trained in using new technology and smart devices \\
& Our firm recruits staff with advanced technology skills \\
\hline MS1 & Management Support \\
MS2 & Top/middle managers are committed to reduce waste and save energy \\
\hline EI1 & Ourddle managers take necessary decisions to foster sustainability in the firm \\
EI2 & Eurployees' involvement \\
EI3 & Our employees are concerned with protecting the environment \\
\hline
\end{tabular}

\subsection{Data Collection}

The frame of the SMEs population is originated from datasets of the Romanian National Trade Register Office. 748 SMEs were selected by means of stratified random sampling to reflect various sizes of enterprises from textile industry in Romania. In addition, the selected SMEs are screened and revised based on their accessibility using active contact data (e.g., phone, email, websites, personal contact data). 427 self-administering questionnaires with cover letters, that assure confidentiality and aggregation of data, were distributed to owners and top managers in manufacturing and operations positions using personal contact (phone calls and face-to-face) to ensure an acceptable response rate. Follow-up phone calls and email rounds were conducted every two weeks to maximise the response rate, from September to December 2017. Of 273 returned questionnaires, 221 are completed and ready for further analysis, yielding an acceptable response rate of $51.76 \%$ [46,47]. To ensure the adequacy of the responses, preliminary $t$-tests were conducted following Lohr's [48] extrapolation procedures for non-response bias. The independent sample $t$-test between late and early returned responses is found to be insignificant ( $p=0.19,0.24$ and 0.13 , respectively). Additionally, a truncated version of the questionnaire is randomly sent again to 98 non-respondent managers via email, to secure a comparative nonresponse sample. The $t$-test between the earliest 20 complete responses from non-respondents and the original respondents' answers concedes an insignificant difference $(p=0.21,0.09$ and 0.15 , respectively). Accordingly, non-response bias cannot be considered as a critical issue.

\subsection{Data Analysis and Results}

The partial least squares approach to structural equation modelling (PLS-SEM) using the SmartPLS 3.0 software SmartPLS GmbH, Bönningstedt, Germany) is applied to analyse the research data through two phases involving assessing the measurement model and testing the structural model [49].

Hair [46] indicated that PLS-SEM was originally designed for prediction purposes so that it is preferred over covariance based SEM software. PLS-SEM is also less sensitive to sample size so that multivariate normal sample data is not strictly necessary [50]. Moreover, the results of the kurtosis and skewness values of the measurement model are between \pm 1 which indicate no violation of normality assumptions of the sample data. The quality of the measurement model is also evaluated by various measures. The standardised outer factor loading for constructed items in Table 2 are considered highly satisfactory as they exceed the threshold value of $0.70(p<0.001)$, except for two constructs that are considered adequate as they exceed the acceptable threshold value of 0.60 [46]. Table 3 shows that 
the values of Cronbach's alpha, composite reliability (CR) and rho_A are greater than 0.707 which indicates the acceptable internal reliability of all variables [51].

Table 2. Standardized factor loading.

\begin{tabular}{|c|c|c|c|c|c|c|c|c|c|c|c|c|}
\hline Items & EI & EP & ER & MS & OPC & OPD & OPA & OPQ & SM & TC & TI & VIF \\
\hline EI1 & 0.712 & & & & & & & & & & & 1.203 \\
\hline EI2 & 0.807 & & & & & & & & & & & 1.271 \\
\hline EI3 & 0.752 & & & & & & & & & & & 1.287 \\
\hline EI1 & & 0.978 & & & & & & & & & & 1.997 \\
\hline EP2 & & 0.725 & & & & & & & & & & 2.041 \\
\hline EP3 & & 0.631 & & & & & & & & & & 2.295 \\
\hline ER1 & & & 0.852 & & & & & & & & & 1.203 \\
\hline ER2 & & & 0.821 & & & & & & & & & 1.202 \\
\hline MS1 & & & & 0.926 & & & & & & & & 1.847 \\
\hline MS2 & & & & 0.899 & & & & & & & & 1.845 \\
\hline OPC1 & & & & & 0.772 & & & & & & & 1.213 \\
\hline OPC2 & & & & & 0.753 & & & & & & & 1.278 \\
\hline OPC3 & & & & & 0.708 & & & & & & & 1.167 \\
\hline OPD1 & & & & & & 0.881 & & & & & & 1.472 \\
\hline OPD2 & & & & & & 0.878 & & & & & & 1.471 \\
\hline OPA1 & & & & & & & 0.801 & & & & & 1.726 \\
\hline OPA2 & & & & & & & 0.857 & & & & & 1.963 \\
\hline OPA3 & & & & & & & 0.736 & & & & & 1.652 \\
\hline OPA4 & & & & & & & 0.788 & & & & & 1.763 \\
\hline OPQ1 & & & & & & & & 0.811 & & & & 1.872 \\
\hline OPQ2 & & & & & & & & 0.709 & & & & 1.525 \\
\hline OPQ3 & & & & & & & & 0.801 & & & & 1.849 \\
\hline OPQ4 & & & & & & & & 0.779 & & & & 1.694 \\
\hline OPQ5 & & & & & & & & 0.762 & & & & 1.77 \\
\hline TC1 & & & & & & & & & & 0.853 & & 1.759 \\
\hline TC2 & & & & & & & & & & 0.861 & & 1.803 \\
\hline TC3 & & & & & & & & & & 0.813 & & 1.628 \\
\hline TI1 & & & & & & & & & & & 0.751 & 2.075 \\
\hline TI2 & & & & & & & & & & & 0.86 & 2.04 \\
\hline TI3 & & & & & & & & & & & 0.917 & 1.831 \\
\hline SM1 & & & & & & & & & 0.727 & & & 2.023 \\
\hline SM2 & & & & & & & & & 0.802 & & & 2.511 \\
\hline SM3 & & & & & & & & & 0.661 & & & 1.698 \\
\hline SM4 & & & & & & & & & 0.868 & & & 3.187 \\
\hline SM5 & & & & & & & & & 0.862 & & & 3.711 \\
\hline SM6 & & & & & & & & & 0.703 & & & 2.096 \\
\hline
\end{tabular}

Table 3. Reliability and validity measures.

\begin{tabular}{|c|c|c|c|c|c|c|c|c|c|c|c|c|c|c|c|}
\hline Variable & $\begin{array}{c}\text { Cronbach's } \\
\text { Alpha }\end{array}$ & Rho_A & CR & AVE & EI & EP & ER & MS & OPC & OPD & OPA & OPQ & SM & TC & TI \\
\hline EI & 0.707 & 0.72 & 0.803 & 0.577 & $\underline{0.75}$ & & & & & & & & & & \\
\hline EP & 0.728 & 0.7 & 0.807 & 0.587 & $\overline{0.22}$ & $\underline{0.76}$ & & & & & & & & & \\
\hline ER & 0.761 & 0.88 & 0.862 & 0.765 & 0.17 & $\overline{0.22}$ & $\underline{0.82}$ & & & & & & & & \\
\hline MS & 0.802 & 0.78 & 0.908 & 0.833 & 0.18 & 0.08 & $\overline{0.04}$ & $\underline{0.88}$ & & & & & & & \\
\hline OPC & 0.768 & 0.69 & 0.788 & 0.558 & 0.29 & 0.35 & 0.08 & $\overline{0.16}$ & $\underline{0.73}$ & & & & & & \\
\hline OPD & 0.721 & 0.71 & 0.875 & 0.781 & 0.4 & 0.41 & 0 & 0.11 & $\overline{0.44}$ & $\underline{0.84}$ & & & & & \\
\hline OPA & 0.809 & 0.81 & 0.871 & 0.634 & 0.35 & 0.36 & 0.02 & 0.22 & 0.35 & 0.57 & $\underline{0.78}$ & & & & \\
\hline OPQ & 0.832 & 0.82 & 0.879 & 0.6 & 0.49 & 0.55 & 0.06 & 0.15 & 0.53 & 0.69 & $\overline{0.57}$ & $\underline{0.74}$ & & & \\
\hline SM & 0.863 & 0.84 & 0.898 & 0.599 & 0.54 & 0.47 & 0.03 & 0.31 & 0.43 & 0.59 & 0.55 & $\overline{0.73}$ & $\underline{0.75}$ & & \\
\hline TC & 0.799 & 0.78 & 0.88 & 0.711 & 0.01 & -0.01 & 0.01 & 0.08 & 0.04 & 0.08 & 0.03 & 0.02 & $\overline{0.11}$ & $\underline{0.81}$ & \\
\hline TI & 0.835 & 0.9 & 0.881 & 0.718 & -0.07 & -0.03 & 0.03 & -0.24 & -0.08 & -0.03 & 0.01 & -0.05 & -0.09 & $\overline{-0.17}$ & $\underline{0.83}$ \\
\hline
\end{tabular}

Notes: EI-employees' involvement; EP-environmental pressures; ER-environmental regulations; MS—management support; OPC—cost; OPR—responsiveness, OPA—adaptability; OPQ—quality; SM—sustainable manufacturing; TC-technology competence; TI-technology infrastructure. The square roots of the average variance extracted (AVE) are shown as underline italic values along the diagonal line. 
In addition, the minimum average variance extracted (AVE) value (0.558) surpasses the required cut-off value of 0.5 [52], which reveals an adequate convergent validity level. Additionally, we follow the Fornell and Larcker [53] criterion to assess discriminant validity. The square root of the AVE (italic diagonal elements), as shown in Table 3, are higher than the interconstruct correlations. Henseler and Sarstedt [50] devised another measure of discriminant validity using Monte Carlo simulationHetrotrait Monotrait correlations (HTMT) with a threshold value less than 0.90. Table 4 shows that 0.84 is the greatest HTMT correlation ratio which establishes an acceptable discriminant validity level and reflects a satisfactory quality level of the measurement model.

Table 4. Hetrotrait Monotrait correlations (HTMT) ratio.

\begin{tabular}{cccccccccc}
\hline & EI & EP & ER & MS & OPC & OPR & OPA & OPQ & SM \\
\hline EI & & & & & & & & & \\
EP & 0.34 & & & & & & & & \\
ER & 0.21 & 0.43 & & & & & & & \\
MS & 0.2 & 0.12 & 0.09 & & & & & & \\
OPC & 0.52 & 0.52 & 0.18 & 0.25 & & & & & \\
OPR & 0.61 & 0.56 & 0.04 & 0.13 & 0.67 & & & & \\
OPA & 0.48 & 0.45 & 0.06 & 0.27 & 0.48 & 0.75 & & & \\
OPQ & 0.67 & 0.7 & 0.09 & 0.21 & 0.74 & 0.84 & 0.69 & & \\
SM & 0.73 & 0.57 & 0.04 & 0.34 & 0.62 & 0.77 & 0.62 & 0.86 & \\
TC & 0.07 & 0.08 & 0.05 & 0.13 & 0.11 & 0.11 & 0.11 & 0.09 & 0.11 \\
TI & 0.05 & 0.1 & 0.09 & 0.28 & 0.13 & 0.02 & 0.04 & 0.11 & 0.09 \\
\hline
\end{tabular}

\subsection{Testing the Structural Model}

Henseler and Sarstedt [54] consider the standardised path coefficients and $R^{2}$ values of endogenous latent variables determine the quality of the structural model and its predictive competence. The bootstrap method with 999 subsamples using the SmartPLS 3.0 software is applied to test the direction, strength and significance of the hypothesised path coefficients. SEM-PLS indices for model fit include Standardized Root Mean Square Residual SRMR $=0.0738(<0.08), \mathrm{d}_{\text {ULS }}=0.829$ $(<0.95), \mathrm{d}_{\mathrm{G}}=0.846(<0.95)$, Chi- Square $=0.966$ and NFI $=0.827$ demonstrate a significantly reliable and adequate fit (see Table 5) [50].

Figure 2 indicates that 50 percent of variance, adjuster $R^{2}$, in sustainable manufacturing is explained by three factor $(t=6.737, p<0.001)$. Hypotheses $\mathrm{H} 1$ and $\mathrm{H} 2$ predicted that technology determinants positively impact sustainable manufacturing in SMEs. 


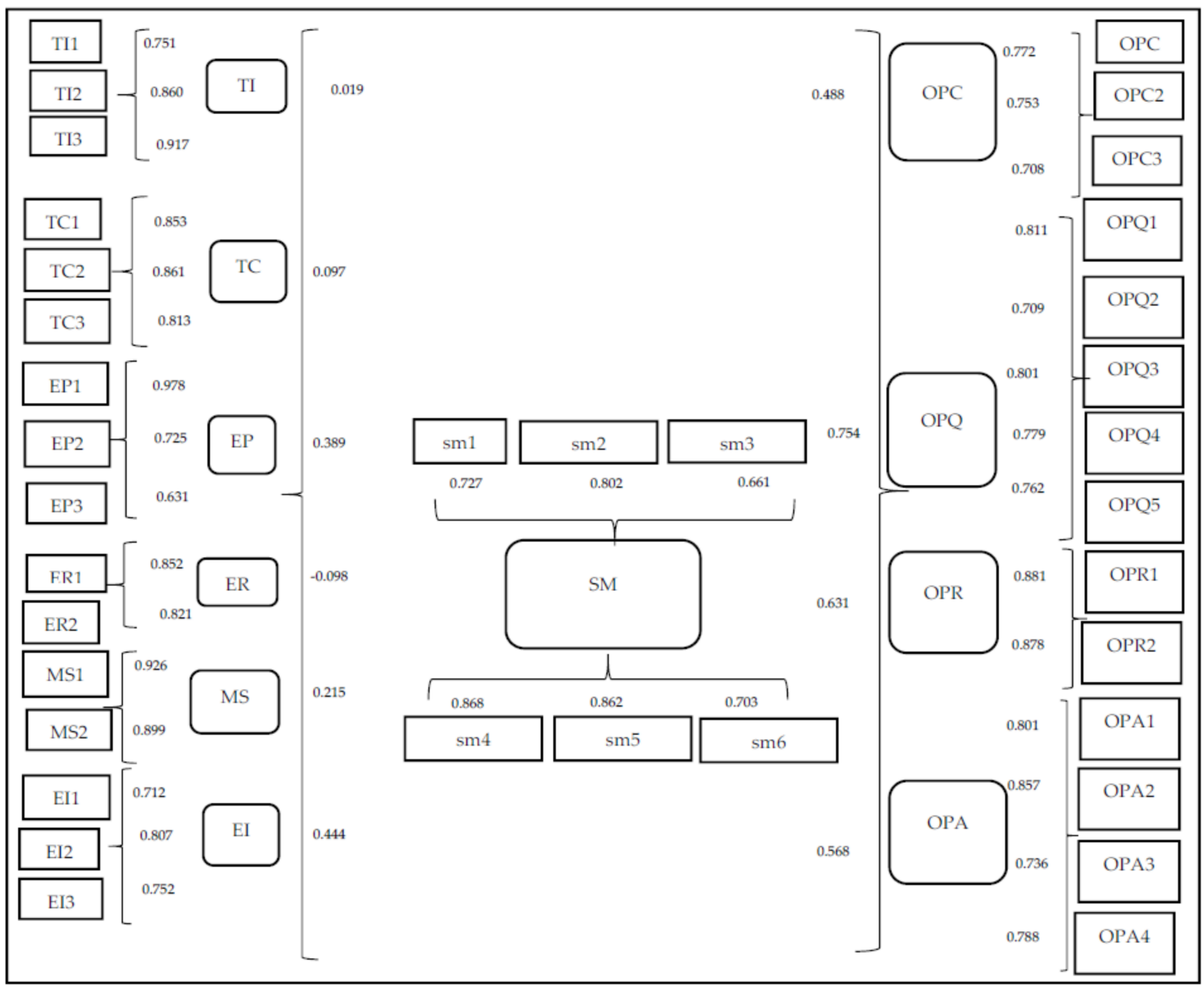

Figure 2. Structural model with path coefficients (b) and adjusted $R^{2}$ values. Note: TI-technology infrastructure; TC-technology competence; $\mathrm{EP}$ - environmental pressures; ER-environmental regulations; MS—management support; EI—employee involvement; SMP—sustainable manufacturing practices; OPC—cost; OPQ—quality; OPR—responsiveness, OPA—adaptability.

As Table 6 shows, the impact of technology infrastructure $(\beta=0.019, t=0.27, \mathrm{~ns})$ and technology competence $(\beta=0.097, t=1.42, \mathrm{~ns})$ are not significant. Thus, $\mathrm{H} 1$ and $\mathrm{H} 2$ are not supported. With regard to environmental determinants, we have found that environmental determinants partially support sustainable manufacturing in SMEs through the significant effect of environmental pressures $(\beta=0.389$, $t=6.86, p<0.001)$. This provides stronger support to hypothesis H3. Unexpectedly, we found a negative and insignificant effect of environmental regulations on sustainable manufacturing in SMEs $(\beta=-0.098, t=1.38, \mathrm{~ns})$ which denotes no support for hypothesis H4. Organisational determinants show a strong impact on sustainable manufacturing which explains a great deal of its variance. Both management support $(\beta=0.215, t=2.51, p<0.01)$, and employees' involvement $(\beta=0.444$, $t=6.83, p<0.001$ ), positively and significantly influence sustainable manufacturing as assumed, supporting hypotheses $\mathrm{H} 5$ and H6. Hypotheses H7, H8, H9 and H10 capture the effect of SMP on competitive capabilities. The coefficients of sustainable manufacturing are positive and significant for cost performance $(\beta=0.488, t=6.73, p<0.001)$, quality performance $(\beta=0.754, t=16.12, p<0.001)$, responsiveness performance $(\beta=0.631, t=11.27, p<0.001)$ and adaptability performance $(\beta=0.568$, $t=9.36, p<0.001)$. 
Table 5. The fit indices of structural model.

\begin{tabular}{ccccc}
\hline Goodness-of-Fit Statistics & Recommended Range & Model 1 & Model 2 & Model 3 \\
\hline & & 0.961 & 0.958 & 0.966 \\
Degree of Freedom & & 97 & 97 & 97 \\
$\left(\chi^{2}\right) / \mathrm{f}$ & $<3.0$ & 1.525 & 1.532 & 1.503 \\
RMR & close to zero & 0.0743 & 0.0751 & 0.0738 \\
GFI & $>0.90$ & 0.914 & 0.916 & 0.91 \\
NFI & $>0.90$ & 0.836 & 0.898 & 0.827 \\
RFI & $>0.90$ & 0.928 & 0.963 & 0.919 \\
TLI & $>0.90$ & 0.972 & 0.981 & 0.969 \\
CFI & $>0.90$ & 0.975 & 0.978 & 0.973 \\
RMSEA & $<0.08$ & 0.044 & 0.045 & 0.043 \\
PCLOSE & $>0.50$ & 0.552 & 0.561 & 0.683 \\
\hline
\end{tabular}

Table 6. Path coefficient and $t$-values of the structural model.

\begin{tabular}{ccccc}
\hline Hypothesis & Path & $\boldsymbol{\beta}$ & $\boldsymbol{t}$-Value & Result \\
\hline H1 & TI-SM & 0.019 & 0.27 & Not supported \\
H2 & TC-SM & 0.097 & 1.42 & Not supported \\
H3 & EP-SM & 0.389 & $6.86^{* *}$ & Supported \\
H4 & ER-SM & -0.098 & 1.38 & Not supported \\
H5 & MS-SM & 0.215 & $2.51^{*}$ & Supported \\
H6 & EI-SM & 0.444 & $6.83^{* *}$ & Supported \\
H7 & SM-OPC & 0.488 & $6.73^{* *}$ & Supported \\
H8 & SM-OPQ & 0.754 & $16.12^{* *}$ & Supported \\
H9 & SM-OPR & 0.631 & $11.27^{* *}$ & Supported \\
H10 & SM-OPA & 0.568 & $9.36^{* *}$ & Supported \\
\hline
\end{tabular}

\section{Discussion}

This study introduces a model that extends our knowledge regarding the determinants of SMP in SMEs and their impact on dimensions of competitive capabilities.

An analysis of survey data from 221 respondents yielded important results that provide support for the influence of the organisational determinants and environmental pressures on SMP. In contrast, the results show no support for the effect of technology determinants on SMP, while the influence of environmental factors is partially maintained. With regard to the consequences of SMP, the findings demonstrate a positively significant impact on competitive capabilities of SMEs. These findings, while partially supporting our hypotheses, provide intriguing insights, especially when compared to the results of prior research. First, as for the effect of technology determinants on SMP, our result did not confirm their significance in influencing SMP. This is inconsistent with previous research [22] which perceived that technology infrastructure and competencies tend to have no influence on SMP. A potential explanation is the lack of technical capacity of SMEs, to recognise, evaluate and take advantage of opportunities associated with sustainability. Second, our result suggests that while environmental pressures from customers, competitors and media significantly influence SMP in Romanian SMEs from the textile industry, environmental regulations do not. This result contradicts prior research that patronises the role of environmental laws and rules in influencing SMP [28]. A plausible interpretation of this finding is the weak enforcement of environmental laws in Romania. In the same vein, previous research also found environmental regulations hardly play any role in regulating SMEs, such as Hamann et al.'s [34] study on wine-producing SMEs in South Africa. With regard to the impact of stakeholder's environmental pressures on SMP, the finding is in harmony with other researchers [32] who emphasised the significant impact of customers, suppliers, media and other stakeholders on implementing SMP. One may argue that many SMEs are subcontractors to large firms, so they are not under direct stakeholder pressures to adopt SMP. A contrary interpretation 
of this argument contemplates the nature of Romanian SMEs, where their locations are scattered across different developing regions; they comprise more than $95 \%$ of the private sector and contribute about $60 \%$ of the Romanian GDP. These features show that they are actually accountable for a notable environmental impact that attracts the attention of various stakeholders. Third, the results confirm prior research concerning the significant impact of organisational determinants on SMP [35]. For SMEs, employees' involvement and top management support are vital for the effective implementation of sustainable programs [55]. In developed countries, SMEs' employees exercise great power over sustainable practices as a result of local authorities' adoption of a dialogue-based rather than a control-based approach concerning sustainable programs at work, as in the case of adopting environmental health and safety schemes in Denmark [56]. However, this impact may have an alternate interpretation. Romanian SMEs are mainly owned and run as sole proprietorships where there is no legal distinction between the owner and the business. Accordingly, managers are likely to influence the enterprise' ethos and the implementation of sustainable practices as a result. Likewise, the limited number of employees, smaller and flatter organisational hierarchies, and an informal working culture allow for effective knowledge transfer among all members and upsurge their involvement to make swift decisions concerning sustainability programs. Though Romanian SMEs lack financial and technological capabilities, their managers and employees tend to recognise and influence SMP to a great extent. Fourth, the findings are similarly in line with our hypotheses on the influence of SMP on competitive capabilities. The findings confirm past research on the impact of sustainable practices on cost, quality, adaptability and responsiveness [37]. Though there are various constraints facing SMEs in countries like Romania, SMP tends to be valuable in promoting competitive performance, which in turn, can reduce the effect of these constraints over the long term. This is in line with Hart [57] that strongly bonds environmental initiatives in product design, production processes, packaging, quality control, responsiveness, sourcing, and so on, to competitive advantages, which can be facilitated by the flexible nature and structure of SMEs [58].

\section{Conclusions}

Understanding the factors and outcomes of sustainable practices is an essential quest at the heart of sustainability research. In contrast to previous studies, this paper is an early attempt to examine SMP in the Romanian context [59]. The study also contributes to the existing body of sustainable manufacturing literature by expanding our knowledge about key factors of SMP in SMEs and introducing the TOE framework to delineate the tenets of these factors. Another significance of this study is linking SMP to competitive capabilities. This link has been barely established in previous sustainable manufacturing research. We proposed a research model that posits the impact of six factors (technology infrastructure, technology competence, environmental pressures, environmental regulations, management support and employees' involvement) on SMP, and the impact of these practices on four competitive capabilities (cost, quality, responsiveness and adaptability). The model is empirically validated by means of the PLS-SEM method using data from 221 owners and managers from Romanian SMEs from textile industry. This study demonstrates that environmental pressures, management support and employees' involvement predicts SMP in Romanian SMEs from the textile industry. In contrast to existing literature, this study establishes that technology infrastructure, technology competence, and environmental regulations do not significantly influence SMP [60,61]. Interestingly, the relationship between SMP and competitive capabilities of Romanian SMEs from the textile industry is positively significant, which supports the contribution of SMP to enhance firms' competitive performance. From a managerial perspective, the present research offers policy makers and managers a frame of reference to boost SMP in the context of SMEs, not only to patronise managers' and employees' environmental responsibility towards various pressures from customers, suppliers and public media but also to encourage their engagement in developing sustainable programs. Therefore, increasing managers' awareness, knowledge and specialised training concerning sustainability issues in SMEs will be of great importance for the textile industry $[62,63]$. Furthermore, Romanian environmental 
authorities need to establish an institutional framework and organizational capacity that reflect SMEs' variations and feedback to enforce the implementation of environmental regulations, so that, accessing, monitoring and reporting actual environmental data by the managers of SMEs will no longer be a difficult process that is scattered among numerous authorities. Great prospects are also expected from sustainable manufacturing technology when the government considers SMEs capacity building by matching technology investments with actual sustainability needs whilst monitoring the textile SMEs role in creating sustainable value at a strategic level.

Although this study provides new insights into SMP in SMEs from the textile industry, the work still has inherent limitations related to data collection and generalization. First, it is suggested that future research on SMP should use a larger sample to better validate the current study in different settings, which further contributes to sustainable manufacturing in organizations. Second, snapshot survey research does not reflect a deep understanding of the context, as in the case of Romanian SMEs from the textile industry, when compared to theory building methods. Therefore, future research should follow a constructive research perspective where reality is created by actors when trying to discover and understand sustainable manufacturing issues (e.g., the role of organizational culture) in similar contexts. Third, it is worth revealing that the impact of environmental regulations and technology factors on SMP necessitate more exploration, and/or comparison between SMEs and large enterprises (i.e., lohn industry) to confirm or refute their effect. Fourth, with regard to the consequences of SMP, the study does not reflect the single impact of each SMP on competitive capabilities. Thus, further research may bring more insights into the relative importance of each practice. Fifth, although the PLS algorithm considers model complexity, discrepancies and uncertainties in the modelling process concerning structural parameters or measurement errors may allow for the application of other approaches that take these uncertainties into consideration $[64,65]$ and compare the results to those mentioned in our study. Finally, upcoming research may use actual performance outcomes rather than self-reported or perceptual data when examining post-implementation practices to gain a true and substantial understanding of the impact of SMP.

Author Contributions: All authors share equal contribution to this paper. All authors wrote the paper and revised the manuscript for intellectual content and read and approved the final manuscript.

Conflicts of Interest: Authors declares no conflict of interest.

\section{References}

1. Carter, C.R.; Rogers, D.S. A framework of sustainable supply chain management: Moving toward new theory. Int. J. Phys. Distrib. Logist. Manag. 2008, 38, 360-387. [CrossRef]

2. Garetti, M.; Mummolo, G.; Taisch, M. Special issue on "sustainable manufacturing". Prod. Plan. Control 2012, 23, 79-82. [CrossRef]

3. Jakob, M.; Marschinski, R.; Hübler, M. Between a rock and a hard place: A trade-theory analysis of leakage under production- and consumption-based policies. Environ. Resour. Econ. 2013, 56, 47-72. [CrossRef]

4. International Trade Administration. How Does Commerce Define Sustainable Manufacturing? U.S. Department of Commerce, 2007. Available online: https:/ / www.oecd.org/sti/ind/45010349.pdf (accessed on 22 December 2017).

5. Huang, A.; Badurdeen, F. Sustainable Manufacturing Performance Evaluation: Integrating Product and Process Metrics for Systems Level Assessement. Procedia Manuf. 2017, 8, 563-570. [CrossRef]

6. Richards, D. Environmentally conscious manufacturing. World Class Des. Manuf. 1994, 1, 15-22. [CrossRef]

7. Seliger, G. Sustainability in Manufacturing: Recovery of Resources in Product and Material Cycles; Springer: Berlin, Germany, 2007.

8. Despeisse, M.; Mbaye, F.; Ball, P.; Levers, A. The emergence of sustainable manufacturing practices. Prod. Plan. Control 2012, 23, 354-376. [CrossRef]

9. Singh, S.; Olugu, E.U.; Fallahpour, A. Fuzzy-based sustainable manufacturing assessment model for SMEs. Clean Technol. Environ. Policy 2014, 16, 847-860. [CrossRef] 
10. Singh, S.; Olugu, E.; Musa, S. Decoupling growth from resource use development of sustainable manufacturing performance evaluation expert system for small and medium enterprises. Procedia CIRP 2016, 40, 608-613. [CrossRef]

11. Seuring, S.; Müller, M. From a literature review to a conceptual framework for sustainable supply chain management. J. Clean. Prod. 2008, 16, 1699-1710. [CrossRef]

12. Agan, Y.; Acar, M.; Borodin, A. Drivers of environmental processes and their impact on performance: A study of Turkish SMEs. J. Clean. Prod. 2013, 51, 23-33. [CrossRef]

13. Thanki, S.; Govindan, K.; Thakkar, J. An investigation on lean-green implementation practices in Indian SMEs using analytical hierarchy process (AHP) approach. J. Clean. Prod. 2016, 135, 284-298. [CrossRef]

14. Entr, D. Public Policy Initiative to Promote the Uptake of Environmental Management Systems in Small and Medium-Sized Enterprises; European Commission: Brussels, Belgium, 2004.

15. Chen, D.; Thiede, S.; Schudeleit, T.; Herrmann, C. A holistic and rapid sustainability assessment tool for manufacturing SMEs. CIRP Ann. 2014, 63, 437-440. [CrossRef]

16. Ramayah, T.; Leen, J.; Marimuthu, M.; Omar, A.; Mohamad, O. Green Manufacturing Practices and Performance among SMEs: Evidence from a Developing Nation; IGI-Global: Hershey, PA, USA, 2013.

17. DePietro, R.; Wiarda, E.; Fleischer, M. The Context for Change: Organization, technology and environment. In The Processes of Technological Innovation; Tornatzky, L.G., Fleischer, M., Eds.; Lexington Books: Lexington, MA, USA, 1990; pp. 151-175.

18. Hwang, B.-N.; Huang, C.; Wu, C. A TOE approach to establish a green supply chain adoption decision model in the semiconductor industry. Sustainability 2016, 8, 168. [CrossRef]

19. Hernandez, A.; Ona, S. Exploring green IT adoption: A case of a business process outsourcing firm. Int. J. Green Comput. 2014, 5, 13-28. [CrossRef]

20. Angeles, R. Wal-Mart's sustainable packaging scorecard initiative through the lens of the technologyorganisation-environment (TOE) framework. Int. J. Sustain. Strateg. Manag. 2012, 3, 270-281. [CrossRef]

21. Angeles, R. Using the technology-organization-environment framework for analyzing Nike's considered index green initiative, a decision support system driven system. J. Manag. Sustain. 2014, 4, 96-103. [CrossRef]

22. Routroy, S.; Kumar, S. An approach to develop green capability in manufacturing supply chain. Int. J. Process Manag. Benchmarking 2016, 6, 1-28. [CrossRef]

23. Chuang, S.; Yang, C. Key Success factors when implementing a green manufacturing system. Prod. Plan. Control 2014, 25, 923-937. [CrossRef]

24. Ifinedo, P. Internet e-business technologies acceptance in Canada's SMEs: An exploratory investigation. Internet Res. 2011, 21, 255-281. [CrossRef]

25. Bhardwaj, B. Role of green policy on sustainable supply chain management. Benchmarking Int. J. 2016, 23, 456-468. [CrossRef]

26. Wong, C.; Lai, W.; Shang, K.; Lu, C.; Leung, T. Green operations and the moderating role of environmental management capability of suppliers on manufacturing firm performance. Int. J. Prod. Econ. 2012, 140, 283-294. [CrossRef]

27. Roni, M.; Jabar, J.; Mohamad, M.; Yusof, M. Conceptual study on sustainable manufacturing practices and firm performance. In Proceedings of the International Symposium on Research in Innovation and Sustainability, ISoRIS'14, Malacca, Malaysia, 15-16 October 2014; pp. 1459-1465.

28. Shankar, K.; Kumar, K.; Kannan, D. Analyzing the drivers of advanced sustainable manufacturing system using AHP approach. Sustainability 2016, 8, 824. [CrossRef]

29. Mittal, V.; Sangwan, K. Development of a model of barriers to environmentally conscious manufacturing implementation. Int. J. Prod. Res. 2014, 52, 584-594. [CrossRef]

30. Govindan, K.; Diabat, A.; Shankar, M. Analyzing the drivers of green manufacturing with fuzzy approach. J. Clean. Prod. 2015, 96, 182-193. [CrossRef]

31. Zhu, Q.; Geng, Y. Drivers and barriers of extended supply chain practices for energy saving and emission reduction among Chinese manufacturers. J. Clean. Prod. 2013, 40, 6-12. [CrossRef]

32. Schrettle, S.; Hinz, A.; Scherrer-Rathje, M.; Friedli, T. Turning sustainability into action: Explaining firms' sustainability efforts and their impact on firm performance. Int. J. Prod. Econ. 2014, 147, 73-84. [CrossRef]

33. Schrader, U.; Fricke, V.; Doyle, D.; Thoresen, V.W. Enabling Responsible Living; Springer: Berlin, Germany, 2013.

34. Hamann, R.; Smith, J.; Tashman, P.; Marshall, R. Why do SMEs go green? An analysis of wine firms in South Africa. Bus. Soc. 2017, 56, 23-56. [CrossRef] 
35. Vinodh, S.; Ramesh, K.; Arun, C. Application of interpretive structural modelling for analysing the factors influencing integrated lean sustainable system. Clean Technol. Environ. Policy 2016, 18, 413-428. [CrossRef]

36. Yusoff, R.; Imran, A.; Qureshi, M.; Kazi, A. Investigating the relationship of employee empowerment and sustainable manufacturing performance. Int. Rev. Manag. Mark. 2016, 6, 284-290.

37. Schoenherr, T. The role of environmental management in sustainable business development: A multi-country investigation. Int. J. Prod. Econ. 2012, 140, 116-128. [CrossRef]

38. Porter, M.; van der Linde, C. Green and competitive: Ending the stalemate. Harv. Bus. Rev. 1995, 73, 128-134.

39. Paul, I.; Bhole, G.; Chaudhari, J. A review on green manufacturing: It's important, methodology and its application. Procedia Mater. Sci. 2014, 6, 1644-1649. [CrossRef]

40. Deif, A. A system model for green manufacturing. J. Clean. Prod. 2011, 19, 1553-1559. [CrossRef]

41. Sezen, B.; Çankaya, S. Effects of green manufacturing and eco-innovation on sustainability performance. Procedia Soc. Behav. Sci. 2013, 99, 154-163. [CrossRef]

42. Rusinko, C.A. Green manufacturing: An evaluation of environmentally sustainable manufacturing practices and their impact on competitive outcomes. IEEE Trans. Eng. Manag. 2007, 54, 445-454. [CrossRef]

43. Conceptia Software Technologies Supplier Scorecard. Available online: http://www.conceptia.in/ (accessed on 18 December 2017).

44. Roberts, N.; Varun, G. Leveraging Information Technology Infrastructure to Facilitate a Firm's Customer Agility and Competitive Activity: An Empirical Investigation. J. Manag. Inf. Syst. 2012, 28, 231-270. [CrossRef]

45. Cooper, D.; Schindler, P. Business Research Methods, 12th ed.; McGraw-Hill Education: New York, NY, USA, 2014.

46. Hair, J. Multivariate Data Analysis, 7th ed.; Pearson: Harlow, UK, 2014.

47. Rotundo, G.; Ausloos, M.; Herteliu, C.; Ileanu, B. Hurst exponent of very long birth time series in XX century Romania. Social and religious aspects. Phys. A Stat. Mech. Appl. 2015, 429, 109-117. [CrossRef]

48. Lohr, S. Sampling: Design and Analysis, 2nd ed.; Brooks/Cole: Boston, MA, USA, 2010.

49. Hair, J. A Primer on Partial Least Squares Structural Equation Modelling (PLS-SEM), 2nd ed.; SAGE: Los Angeles, CA, USA, 2017.

50. Henseler, J.; Sarstedt, M. Goodness-of-fit indices for partial least squares path modelling. Comput. Stat. 2013, 28, 565-580. [CrossRef]

51. Straub, D.; Boudreau, M.; Gefen, D. Validation guidelines for is positivist research. Commun. Assoc. Inf. Syst. 2004, 13, 380-427.

52. Henseler, J.; Ringle, C.; Sarstedt, M. A new criterion for assessing discriminant validity in variance-based structural equation modeling. J. Acad. Mark. Sci. 2015, 43, 115-135. [CrossRef]

53. Fornell, C.; Larcker, D. Evaluating structural equation models with unobservable variables and measurement error. J. Mark. Res. 1981, 18, 39-50. [CrossRef]

54. Henseler, J.; Hubona, G.; Ray, P. Using PLS path modeling in new technology research: Updated guidelines. Ind. Data Syst. 2016, 116, 2-20. [CrossRef]

55. Langwell, C.; Heaton, D. Using human resource activities to implement sustainability in SMEs. J. Small Bus. Enterp. Dev. 2016, 23, 652-670. [CrossRef]

56. Madsen, H.; Ulhøi, J. Stakeholder pressures, environmental impact and managerial initiatives of SMEs: A longitudinal study. J. Transdiscipl. Environ. Stud. 2015, 14, 13-22.

57. Hart, S. A natural-resource-based view of the firm. Acad. Manag. Rev. 1995, 20, 986-1014.

58. Dragan, I.M.; Isaic-Maniu, A. An Alternate for Indicators that Characterize the Structure of Economic Systems. Entropy 2017, 19, 346. [CrossRef]

59. Ceptureanu, S.I.; Ceptureanu, E.G.; Visileanu, E. Comparative analysis of small and medium enterprises organizational performance in clothing industry. Ind. Textila 2017, 68, 156-162.

60. Bey, N.; Hauschild, M.; McAloone, T. Drivers and barriers for implementation of environmental strategies in manufacturing companies. CIRP Ann. 2013, 62, 43-46. [CrossRef]

61. Phungrassami, H. Eco-efficiency as a decision tool for cleaner production: Application for SMEs in Thailand. Environ. Res. J. 2008, 2, 217-221.

62. Wang, L.; Li, Y.; He, W. The Energy Footprint of China's Textile Industry: Perspectives from Decoupling and Decomposition Analysis. Energies 2017, 10, 1461. [CrossRef]

63. Osadolor, O.A.; Lennartsson, P.R.; Taherzadeh, M.J. Introducing Textiles as Material of Construction of Ethanol Bio reactors. Energies 2014, 7, 7555-7567. [CrossRef] 
64. Panda, B.; Garg, A.; Jian, Z.; Heidarzadeh, A.; Gao, L. Characterization of the tensile properties of friction stir welded aluminium alloy joints based on axial force, traverse speed, and rotational speed. Front. Mech. Eng. 2016, 11, 289-298. [CrossRef]

65. Garg, A.; Lam, J.; Gao, L. Power consumption and tool life models for the production process. J. Clean. Prod. 2016, 131, 754-764. [CrossRef] 